\title{
Impact Of E-Atmospheric Elements On The Perceived Value Of The Online Visit
}

Ahmed Anis Charfi, European Business School Paris, France

Eric Lombardot, University of Paris 1 Pantheon-Sorbonne, France

\begin{abstract}
Websites managers want the consumption experience to be central in the online visit. This study analyzes the effects of experiential components of a website on the online experience. Through experimentation, we handle three elements of the merchant environment (virtual agent, $3 D$ environment and control command). A survey of 272 users shows that the tools manipulated generate perceived value. Furthermore, we test the effect of hedonic and utilitarian value of the visit on the online behavior, highlighting its significant effect. Finally, from a theoretical and a managerial point of view, we elaborate on the necessary conditions for improving the visitor experience and for creating customer values.
\end{abstract}

Keywords: Online Experience; Virtual Agent; 3D Environment; Control Command; Perceived Value

\section{INTRODUCTION}

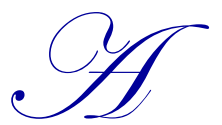

ccording to the IRMBG (Interactive Media in Retail Group), in 2011, 500 millions of websites worldwide generated a turnover of 690 billion Euros (+20\% compared to 2010). In order to reach a potential market of 2.2 billion internet users and differentiate from competitors, webmasters improve the online navigation and shopping experience. Indeed, today, the visual mental imagery dominates the other types of mental imagery (Eroglu et al., 2001; 2003). Thus, the lack of physical contact between the internet users and the products, and the reduction of the retailing space to screen size could be compensated by the rich media through 3D environment, avatars, sounds, images, videos, etc. These technologies, considered as interactive and viewable in real time, bring more realism to the online retailing environment and lead to differentiation. While websites became the main mean for reaching consumers, most transactional platforms offer a very similar design as well as analogous aesthetic and social features. Because of the impact of the online environment on consumers' reactions and behaviors and so on the companies' turnover, a need for staging the transactional websites is rising. It's commonly admitted that using e-atmospherics attracts more customers on commercial websites and generates intense reactions. Furthermore, new perspectives are emerging with convergence. Convergence media and technologies means that virtual worlds are expanding beyond the online space to incorporate environments across the media platforms. For example, with the 4G technology, augmented reality and location-based technology, it becomes possible to create a virtual world experience within a real-world city (Harwood and Ward, 2013).

This research builds on the framework of experiential marketing within transactional environments (McKinney, 2004; Borghini et al., 2009). Merchant websites are now organized, not only to be functional, but to provide emotions and feelings to the customers. The experiential approach aims to transform a shopping experience, offline or online, into anemotionally intense and unique experience, in order to enhance the appreciation and notoriety of the brand.

The goal of this paper is to understand in depth the effects of environmental components of merchant websites on the perceived value of the online experience and its behavior consequences. First, the concepts of online experiential contexts, perceived value and behavior intentions are presented as well as a model linking these variables. Then, an online experimentation is offered and the model hypotheses are tested. Finally, contributions, limitations and further research are discussed. 


\section{CONCEPTUAL FRAMEWORK AND HYPOTHESES}

\subsection{Online Experience And E-Atmospherics}

The consumption experience initially described by Holbrook and Hirschman (1982) has been applied to the internet context. The progress of transactional websites shows the intention of online sellers to establish multisensorial interactions, in particular by the insertion of high quality visuals and stereo sounds (Fiore et al., 2005). The mental process of the consumer is stimulated by the interactivity of the website. This is supposed to generate a state sometimes close to the flow (Hoffman and Novak, 1996). This state of mind influences the consumer's feelings and memories after using the website (Hoffman and Novak, 2009). Therefore, online experiences are getting richer and richer and aim to be as stimulating, if not more, than offline experiences (Dailey, 2004). The new consuming enchantment goes beyond the traditional business boundaries to invest e-business.

On the one hand, the online experience allows all possible actions on a product in an interactive way. Technically, internet users can learn more information on the shape, the texture and the use of a product by moving it and inspecting it under different angles (Li et al., 2001; Suh and Lee, 2005). This is the utilitarian dimension of the experience. On the other hand, the online experience includes a specifically hedonic experience. It depends on the emotional reactions of the user.The experience results in consumer's involvement and can also be evaluated negatively by the consumer (Hoffmann and Novak, 2009).

In order to produce online consumption experiences, an important number of environmental stimuli have been highlighted (Koo et al., 2009). Among these stimuli, we will keep color, music, ads, virtual agents, images, video and 3D presentation (Suh and Lee, 2005;Kim and Forsythe, 2008). All these stimuli impact the consumer on various levels, in particular cognitive, affective and behavioral. The environmental elements selected and tested in this paper have been chosen according to Baker's typology (1994) about environmental attributesand applied to online experiences: social factors (presence or absence of a virtual agent), atmosphere factors (atmosphere and environment in 3D or not) and design factors (presence or not of a control command). Indeed, Dailey (2004) has shown that this typology could be used online as well as offline.

\subsection{Perceived Value As A Behavioral Antecedent}

In a traditional approach of offline consumption, the perceived value of the visit of amerchant environmentplays a central mediating role. It is about an evaluative judgment of the confrontation between the benefits and the sacrifices associated to a consumption experience (Holbrook and Hirschman, 1982; Holbrook, 1999). The perceived value allows predicting the future behavior of the subject instead of satisfaction (Filser, 2008). Perceived value is composed of two dimensions: the hedonic and the utilitarian value (e.g., Babin et al., 1994).

The utilitarian dimension of perceived value is the result of reasoned actions orientated towards the achievement of a precise goal. It depends on the functional attributes of the experience and calls to consumer's rationality and objectivity. This aspect could be, for example, highlighted during a purchasing experience thanks to a practical posted price and a clear merchandising strategy. The hedonic dimension of perceived value refers to the subjective aspect of the shopping experience including pleasure, fascination and escape(Holbrook and Hirschman, 1982). Here, purchasing isn't the point, the consumer focus on the intangibles attributes of the visit.

Applied to online environments, the perceived value depends on the interaction between the subject and the object during the visitingexperience, considering both utilitarian and hedonic dimensions (Wang et al., 2007). A website offering a high utilitarian value is designed to resolve a specific problem (e.g. obtaining directions or buying products) with adapted tools. A website offering a high hedonic value is designed to provide self-fulfilling value and enjoyment to the consumer. Both utilitarian and hedonic values influence service satisfaction, customer loyalty and behavior intentions (Koo et al., 2009).

In order to evaluate the impact of the environmental stimuli of a website, the following hypotheses are suggested, considering that e-atmospheric enhances both dimensions of perceived value. 
First, virtual agents play the role of customer advisers; they embody the human presence of the selling platform. If the most common criticism addressed to selling platforms is their impersonal nature, virtual agents constitutes a relevant solution (Holzwarth et al., 2006). Indeed, they set up a new way of communicating with the brand; they participate to the products or services presentation and to the interaction between the website and the user.

H1: presence (vs. absence) of a virtual agent positively influences the utilitarian dimension of perceived value.

H2: presence (vs. absence) of a virtual agent positively influences the hedonic dimension of perceived value.

Secondly, a selling website offers various paths and functionalities which allow participants to control the content of the selling platform as well as the experience proceedings (Jiang and Benbasat, 2005). Indeed, the control perception by the user let him appropriate himself the online experience (Carù and Cova, 2004). This control feeling is a structuring strength of the activity orientated toward the need to demonstrate his skill, his superiority and his mastering of the environment (White, 1959). Thus, it constitutes a major component of the selling website atmosphere (Mathwick and Rigdon, 2004). The control concept has been the subject of many papers in psychology (e.g.,Whiter, 1959), however, very few studies have been conducted on this essential phenomenon in the context of an online consumption experience.

H3: presence (vs. absence) of a control command positively influences the utilitarian dimension of perceived value.

H4: presence (vs. absence) of a control command positively influences the hedonic dimension of perceived value.

Finally, if the virtual environment is devoid of tactile, olfactory and gustatory characteristics, it uses entirely visual and auditive aspects. 3D interfaces offer the user a rich experience and give him the illusion of being elsewhere. The user's senses are then stimulated to the point of feeling the virtual environment presence or even, of feeling in immersion (Jin, 2009). These 3D environments supply more information about the products, facilitate the research (Lynch and Ariely, 2000) and improve the access to the consuming experience.

H5: presence (vs. absence) of a 3D environment positively influences the utilitarian dimension of perceived value.

H6: presence (vs. absence) of a 3D environment positively influences the hedonic dimension of perceived value.

\subsection{Behavior Intentions}

Virtual environments aim to have positive impacts on the cognitive evaluation of the internet user as well as on his feelings (Dailey, 2004; Hoffman and Novak, 2009). The previous works, focusing on perceived value, demonstrated it generates effects on the exploratory user's behavior, on the attitude toward the website, on the intention-to-purchase or even on satisfaction (Luna et al., 2002; Choi, Kim, and Kim, 2007). These behavioral intentions areresulting from the perceived value of the website visit. In effect, numerous works on perceived value consider it as an antecedent of intention-to-buy (e.g.,Luna, Perrachio and de Juan, 2002), word-of-mouth (e.g., Derbaix et al., 2010), intention to visit again (Luna, Perrachio and de Juan, 2002; Hong and Kim, 2004) and of all behavioral intentions (Baker et al., 2002). The consumer behavior after exposure to a merchant stimulus are sensitive to evaluate because of the temporal gap they imply (Kotler and Keller, 2011). Thus, the estimation of intentions is the most commonly used compromise in the field of consumer behaviors. The intention to purchase (Putrevu and Lord, 1994) seems to be the most determining measure of efficiency:

H7: The utilitarian dimension of perceived value influences positively the intention to purchase.

H10: The hedonic dimension of perceived value influences positively the intention to purchase.

Nevertheless, it appears relevant to complete online efficiency by the intention of word-on-mouth (Zeithaml et al., 1996): 
H9: The utilitarian dimension of perceived value influences positively the intention of word-on-mouth.

H12: The hedonic dimension of perceived value influences positively the intention of word-of-mouth.

And intention to revisit the website (Supphellen and Nysveen, 2001):

H8: The utilitarian dimension of perceived value influences positively the intention to visit the website again.

H11: The hedonic dimension of perceived value influences positively the intention to visit the website again.

In Figure 1 we summarize the different hypotheses tested:

\begin{tabular}{|c|c|c|c|c|}
\hline Environmental & \multirow{4}{*}{$\mathrm{H} 1$ to $\mathrm{H} 6$} & Perceived Value & \multirow{2}{*}{$\mathrm{H} 7$ to $\mathrm{H} 12$} & Behavior Intentions \\
\hline Elements & & Utilitarian & & Intention to purchase \\
\hline Virtual Agent & & Hedonic & & Intention to revisit \\
\hline$\frac{\text { Control command }}{3 \mathrm{D}}$ & & & & Word-of-mouth \\
\hline
\end{tabular}

Figure 1: Predicted Relationships

\section{METHODOLOGY}

\subsection{The Selected Website}

In order to test our hypotheses, a specific website, which presents the company Cogedim Immobilier ${ }^{1}$ and its products, was created and put online. The choice of a unique website allows observing the inter-individual variance of a sample subjected to the same stimuli. The choice of this website is justified insofar as it has many experiential components. The merchant environment includes virtual agents. These avatars that embody the human presence on the website introduce a new form of dialogue with the brand.They contribute to the presentation of the offer and the interaction between the website and the user.These characters question the users in order to know better their needs and expectations (financing types, length, amount, etc...) and users have to answer to go further in the process. The website also features a three-dimensional interface that combines audio, video and imagesand a control command for the internet user. These e-atmospherics, accompanied by high quality and size images, hold the internet user's attention.By the intermediary of experimentation, a complete factorial plan was set up. It implies the conception of $2 * 2 * 2=8$ versions of the same website: ${ }^{1}$ Cogedimis a company specialized in financing real estate. The choice to work on the website of this company is incorporated within the
framework of a partnership with NovacomGroupe, which designed the website of Cogedim-Real Estate. 

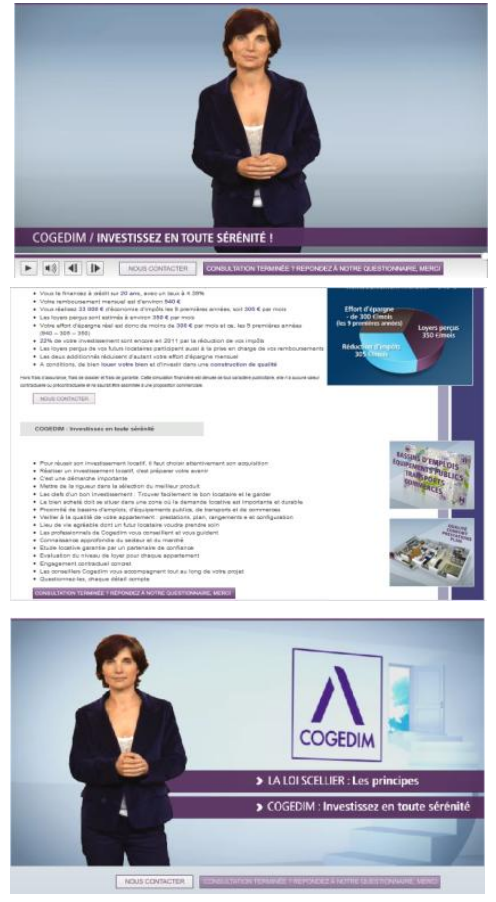

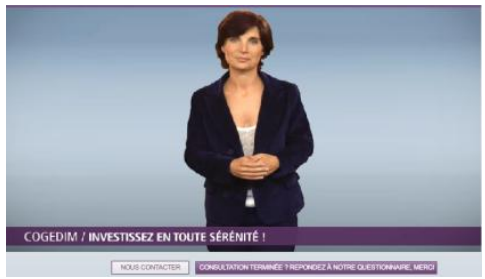

8 versions tested:

- Virtual agent $(\mathrm{Y} / \mathrm{N})$

- Control command $(\mathrm{Y} / \mathrm{N})$

- $\quad 3 D(Y / N)$

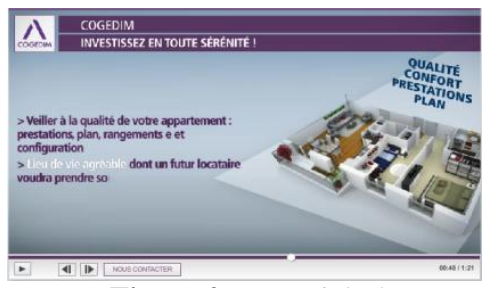

Figure 2: Factorial Plan
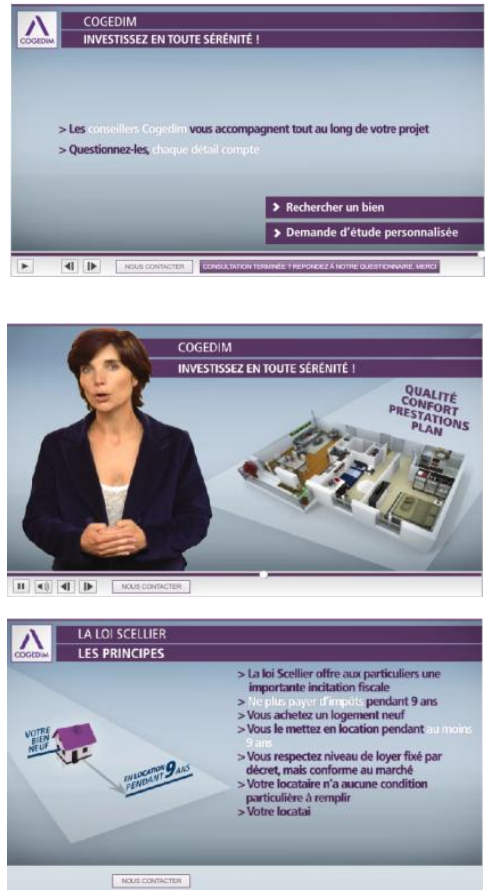

\subsection{Measurement}

Pre-existing scales have been adapted to measure the various constructs of this study. All dimensions have been measured on a seven-point Likert scale. To measure the perceived value, we used the scale of Babin et al. (1994). It is composed of 6 items and of 2 dimensions (hedonic/utilitarian) which allows to analyze the online shopping aspects in a satisfactory way. The scale used to measure the intention to purchase is Putrevu and Lord's one (1994). It comprises 2 items and has already proven its worth in e-business studies(Kekeff and Webster, 2006). To measure the intention to visit the website again, the mono-item scale of Supphellen and Nysveen(2001) was selected. It has been fully tried and tested in various researches (Hong and Kim, 2004). Finally, the intention of word-on-mouth was measured by 3 items according to Zeithmal et al. (1996).Some of these scales have been created to evaluate physical environment but are commonly used in virtual environment.

\subsection{Data Collection}

During the experimentation, each subject was invited to browse on the website without specific instructions. Then, the user answered an online questionnaire. In order to make up a homogeneous sample of subjects in terms of expertise, the links to visit the website were sent randomly by e-mail to the company's customers who registered on their own initiative. The sample is composed of 272 respondents ( 34 by version) of which $52.5 \%$ are women and $47.5 \%$ are men. They are all between 18 and 61 years old. Before we carried out the analysis, we controlled for age, gender, level of education and occupation. A multivariate analysis of variance (MANOVA) shows that the random distribution of subjects among the 8 groups is satisfactory.

\subsection{Experimental Verification}

A manipulation check allows detecting the respondents who didn't follow the experimentation guidelines (Oppenheimer et al., 2009). If subjects don't perceive the presence or the absence of the e-atmospherics, it is impossible to examine the impact of these elements of the website on the perceived value. The mean comparison test is convincing and states that during their visits, the users were faced to the e-atmospherics manipulations. 


\subsection{Statistics Tests Employed}

Hypotheses $H 1$ to $H 6$ concern the influence of binary variables (presence vs absence of one of the eatmospherics) on the mean level of perceived value (quantitative variable estimated using Likert scale).Thus, we tested these hypotheses $H 1$ to $H 6$ by using variance analysis (ANOVA). Hypotheses $H 7$ to $H 12$ concern the multiple correlation links between latent variables (perceived value and behavior intentions measured on aLikert scale).Hypotheses $H 7$ to H12are therefore tested by using structural equations modeling (SEM) with AMOS.

\subsection{Reliability, Validity And Model Fit}

Exploratory factor analyses showed a satisfactory level of reliability and validity for the various measures used. Cronbach's $\alpha$, Jöreskog's $\rho$ and $\rho_{\mathrm{cv}}$ are satisfactory for all the constructs. Testing for discriminant validity indicates that each construct of the model is at the same time unique and different from the others (Farnell, 2009). The variance shared by different constructs is inferior to the average variance indicator extracted for each construct. The Table 1 shows that the constructs are discriminated enough between themselves. A confirmatory factor analysis allowed evaluating the adequacy of the measured model by the structural equation model. The absolute and parsimony fit indexes are satisfactory (Arbuckle, 2006).

Table 1: Reliability, Validity Of The Constructs And Model Fit

\begin{tabular}{|c|c|c|c|c|c|c|}
\hline & $\alpha$ & $\bar{\rho}$ & $\mathrm{PV}$ & WOM & IP & IR \\
\hline Perceived value (PV) & .786 & .832 & .680 & & & \\
\hline Word-of-mouth (WOM) & .933 & .957 & .663 & .881 & & \\
\hline Intention to purchase(IP) & - & - & .582 & .829 & .931 & \\
\hline Intention to revisit(IR) & - & - & .630 & .803 & .796 & 1 \\
\hline
\end{tabular}

\section{RESULTS}

For the atmospheric elements (Table 2), the presence of a virtual agent has a significant influence on the hedonic dimension of the perceived value but not on the utilitarian dimension ( $H 1$ is rejected, $H 2$ is supported). The avatar creates a feeling of social presence and of interpersonal interactions. It confirms prior research exploring the effects of online social signals on emotional and affective reactions (Holzwarth et al., 2006). The effect is positive even if the avatar doesn't facilitate directly the information search. Moreover, the presence of a control command and of 3D elements significantly influence the utilitarian dimension of the perceived value but not the hedonic dimension ( $\mathrm{H} 3$ and $\mathrm{H} 5$ are supported, $\mathrm{H} 4$ and $\mathrm{H} 6$ are rejected). The command lets an impression of autonomy and a better navigation control. Thus, the internet user is involved in the process and pays a maximal attention to the content offer. The 3D renders the visit more realistic and creates an illusion of proximity which strengthens also the attention paid to the content.

Table 2: Test Of E-Atmospherics Influence On The Perceived Value (ANOVA)

\begin{tabular}{|c|c|c|c|c|}
\hline & & Mean & $\mathrm{F}$ (p-value) & Hypotheses \\
\hline \multirow{6}{*}{$\begin{array}{l}\text { Perceived value: } \\
\text { utilitarian dimension } \\
\text { (PVU) }\end{array}$} & Avatar presence $_{\text {. }}$ & .0702261 & \multirow{2}{*}{$\begin{array}{l}1.343 \\
(.248)\end{array}$} & \multirow{2}{*}{ H1 rejected } \\
\hline & Avatar $_{\text {absence }}$ & -.0702261 & & \\
\hline & Control command presence & .1920657 & \multirow{2}{*}{$10.381(.001)$} & \multirow{2}{*}{ H3 supported } \\
\hline & Control command absence & -.1920657 & & \\
\hline & $3 \mathrm{D}_{\text {presence }}$ & .2067026 & \multirow{2}{*}{$12.097(.001)$} & \multirow{2}{*}{ H5 supported } \\
\hline & $3 \mathrm{D}_{\text {absence }}$ & -.2067026 & & \\
\hline \multirow{6}{*}{$\begin{array}{l}\text { Perceived value: } \\
\text { hedonic dimension } \\
(\mathrm{PVH})\end{array}$} & Avatar $_{\text {presence }}$ & .3574740 & \multirow{2}{*}{$39.725(.000)$} & \multirow{2}{*}{ H2 supported } \\
\hline & Avatar $_{\text {absence }}$ & -.3574740 & & \\
\hline & Control command presence & .0587891 & \multirow{2}{*}{$\begin{array}{c}.940 \\
(.333) \\
\end{array}$} & \multirow{2}{*}{ H4 rejected } \\
\hline & Control command absence $_{\text {. }}$ & -.0587891 & & \\
\hline & $3 \mathrm{D}_{\text {presence }}$ & .0096054 & \multirow{2}{*}{$\begin{array}{c}.025 \\
(.874)\end{array}$} & \multirow{2}{*}{ H6 rejected } \\
\hline & $3 \mathrm{D}_{\text {absence }}$ & -.0096054 & & \\
\hline
\end{tabular}


Finally, the structural equations modeling (Table 3) supports the positive effect of the two dimensions of perceived value on the three kinds of behavior intentions ( $H 7$ to $H 12$ are supported). Despite the utilitarian goal of the visit, the internet user is more attracted by emotional and affective stimulations. The central role of perceived value in the evaluation process of the efficiency of an online consumption experience is confirmed.

Table 3: Test Of The Influence Of Perceived Value On The Behavior Intentions (SEM)

\begin{tabular}{|c|c|c|c|c|c|}
\multicolumn{1}{c|}{} & $\beta$ stand. & S.E. & C.R. & p-value & Hypotheses \\
\hline $\mathrm{PVU} \rightarrow \mathrm{IP}$ & .725 & .353 & 5.190 & .000 & H7 supported \\
\hline $\mathrm{PVU} \rightarrow \mathrm{IR}$ & .656 & .411 & 5.219 & .000 & H8 supported \\
\hline $\mathrm{PVU} \rightarrow$ WOM & .651 & .372 & 5.201 & .000 & H9 supported \\
\hline $\mathrm{PVH} \rightarrow \mathrm{IP}$ & .612 & .049 & 10.423 & .000 & H10 supported \\
\hline $\mathrm{PVH} \rightarrow \mathrm{IR}$ & .577 & .058 & 10.948 & .000 & H11 supported \\
\hline $\mathrm{PVH} \rightarrow$ WOM & .688 & .054 & 12.624 & .000 & H12 supported \\
\hline
\end{tabular}

\section{DISCUSSION, LIMITATIONS AND FURTHER RESEARCH}

From a practical point of view, the entertaining nature of the visit constitutes a central differentiation factor which impacts the intention to purchase as well as the will to visit again the website and to share this experience. Over purchasing in it-self, the online consumer looks for manipulations, entertainment, physical and psychical comfort, evasion, aesthetics and emotional pleasure, social interactions. Thus, transactional website managers must give more importance to create online experiences. In a hypercompetitive environment, both of the hedonic and the utilitarian dimensionsare necessary todifferentiate a website.

To improve the online experience, many factors have been identified: entertainment and evasion feelings, immersion, interactivity, stimulating environment, control feeling and user activity, virtual presence, learning and knowledge, customization or aesthetic (Garnier and Poncin, 2013).The e-atmospherics, create a more friendly and realistic ambiance with the 3D (Jin, 2009), but also bring a social presence thanks to an avatar (Chung, 2005).This contributes to disconnect easily from reality and to facilitate immersion. The internet user immerges himself more easily in a virtual environment and becomes a part of it. The experience is enriched by its immersion aspect and is more realistic by the re-introduction of a body. Indeed, it has been proven that a body representation influences information gathering process, attitudes formation as well as memorization (Garnier and Poncin, 2013).

The ability of the user to have a better control with a command offers him an increased autonomy. The reinforced interactivity finally commits more the internet user in the experience than a passive situation, strengthens his choices and produce a proximity feeling with the brand (Jiang and Benbasat, 2005). Thus, by creating compelling online virtual experiences with products or services, advertisers can enhance the value of the product information presented, engage consumers in an active shopping experience, increase the number of unique and repeat traffic visitors for a site, and ultimately establish an online competitive advantage ( $\mathrm{Li}$ et al., 2002). Virtual experiences allow for vicarious consumption because consumers are actively engaged in the inspection, control or creation of a product or service in 3D advertising rather than being a passive observer as in more traditional media. Furthermore, a high informationcontrol in e-commerce environments has been foundto improve consumer decision quality and knowledge(Ariely, 2000). This level of control brings to a simulation of a consumption experience, which has become increasinglyimportant as society moves toward an experienceeconomy (Pine and Gilmore 1998).From a more theorical point of view, the perceived value is straightly influenced by the atmospherics variables and its role to predict behaviors is reinforced. Thus, satisfaction is well substituted by perceived value (Filser, 2008).

The results of this study include some limitations and call for further research. First of all, the website selected for the experimentation offers real-estate financing solutions. It is a long decision process including a large searching phase. So, it would be relevant to broaden this study to websites offering other kinds of products and services.

Furthermore, e-atmospherics have been tested through a binary way, for example presence or absence of an avatar. It seems to be interesting to take in account some specificities of the avatar, as its attractiveness or its 
isomorphic characteristics (Holzwarth, 2006). Indeed, it appears necessary to any manager wanting to use an avatar on his website to question the avatar appearance and how it is perceived in terms of credibility, expertise, congruence with the company, performance, satisfaction (Garnier and Poncin, 2013). In this paper, the avatar represents a selling agent controlled by the company and not the internet user, customizable and controlled by the user himself, as in many researches concerning online role-plays (such as Second Life, the Sims...). These researches highlights that the customization of the avatar by the user allows him to express his values and characteristics. The process can be long and ask an important involvement. Characters evolve but this customization modifies deeply and positively the online experience. Further research could investigate the possibilities to allow the internet user to customize the commercial agent. What could be the impacts on involvement, immersion, perceived value or fidelity?Then, some individual variables could play a moderator role in the proven efficiency mechanisms (i.e, internet expertise or involvement in the product category). Finally, Babin et al. (1994) approach of perceived value leads to reduce the concept to two dimensions while other authors gives a wider definition, as Holbrook (1999) or Mencarelli (2008).

\section{AUTHOR INFORMATION}

Ahmed Anis Charfi, European Business School Paris, France

Dr. Ahmed Anis Charfi is professor of Marketing at European Business School - Paris. His research interests are about global Marketing, E-Marketing, E-Commerce, Consumer Behavior, CRM, Consumption Experience.

E-mail: anischarfi@ebs-paris.com

Eric Lombardot, University Paris 1 Panthéon-Sorbonne, PRISM Sorbonne, France

Dr. Eric Lombardot is associate professor at Paris 1 Panthéon-Sorbonne University (PRISM Sorbonne). His research interests are about advertising impact, ethical consumption and consumer behavior.

Email: eric.lombardot@univ-paris1.fr

\section{ACKNOWLEDGMENTS}

The authors would like to thank Claire Lataste for her contribution to the article.

\section{REFERENCES}

1. Arbuckle J.L. (2006), Amos 7.0 User's Guide, PA: Amos Development Corporation, Spring House.

2. Ariely D. (2000), Controlling the Information Flow: Effects on Consumers' Decision Making and Preferences, Journal of Consumer Research, 27 (2), 233-249.

3. Babin B. J., Darden W.R. \& Griffin M. (1994), Work And/Or Fun: Measuring Hedonic And Utilitarian Shopping Value, Journal Of Consumer Research, 20 (4), 644-656.

4. $\quad$ Baker J., Grewal D. \&Parasuraman A. (1994), The Influence Of The Store Environment On Quality Inferences And Store Image, Journal Of The Academy Of Marketing Science, 22 (4), 328-339.

5. Chung D. (2005), Something For Nothing: Understanding Purchasing Behaviors In Social Virtual Environment. Cyberpsychology\& Behavior, 8 (6), 538-554.

6. Dailey L. (2004), Navigational Web Atmospherics Explaining The Influence Of Restrictive Navigation Cues, Journal Of Business Research, 57 (7), 795-803.

7. Derbaix M., Leheut E., Derbaix C. \& Stenmans G. (2010), Gratuité, valeur perçue et consentement à payer: une application aux matchs de l'équipe nationale Belge de basket-ball, Décisions Marketing,59, 17-28.

8. Eroglu S. A., Machleit K. A. \& Davis L. M. (2003), Empirical Testing Of A Model Of Online Store Atmospherics And Shopper Responses, Psychology \& Marketing, 20 (2), 139-150.

9. Farrell, A. M. (2009). Insufficient Discriminant Validity: A Comment On Bove, Pervan, Beatty And Shiu. Journal Of Business Research, 63(3), 324-327.

10. Filser M. (2002), Le marketing de la production d'expériences: statut théorique et implications managériales, Décisions Marketing, 28, Septembre-Décembre, 13-22.

11. Filser M. (2008), Décision, expérience et valeur de consommation: esquisse d'un nouveau cadre théorique pour l'analyse du comportement du consommateur, Revue Sciences De Gestion, 64, $27-41$. 
12. Fiore A.M., Jin H-J.\& Kim J. (2005), For Fun And Profit: Hedonic Value From Image Interactivity And Responses Toward An Online Store. Psychology \& Marketing, 22 (8), 669-694.

13. Garnier M. \& Poncin I. (2010), L'expérience sur un site de vente 3D. Le vrai, le faux et le virtuel:àlacroisée des chemins, Management et Avenir, 32 (2), 173-191.

14. Garnier M. \& Poncin I. (2013), L’avatar en marketing: synthèse, cadre intégrateur et perspectives, Recherche et Applications en Marketing, 28 (1), 92-123.

15. Harwood T.G. \& Ward J. (2013), Market research within 3D virtual worlds, International Journal of Market Research, 55 (2), 247-266.

16. Hoffman D.L. \& Novak T.P. (1996), Marketing In Hypermedia Computer-Mediated Environments: Conceptual Foundations, Journal Of Marketing, 60 (3), 50-68.

17. Hoffman D.L. \& Novak T.P. (2009), Flow Online: Lessons Learned And Future Prospects, Journal Of Interactive Marketing, 23 (1), 23-34.

18. Holbrook M.B. \& Hirschman E.C. (1982), The Experiential Aspects Of Consumption: Consumer Fantasies, Feelings And Fun, Journal Of Consumer Research, 9, September, 132-140.

19. Holbrook M.B. (1999), Introduction To Consumer Value, In Holbrook, M. B. (Ed), Consumer Value: A Framework For Analysis And Research, Routledge, London, 1-28.

20. Holzwarth M., Janiszewski C. \& Neumann M.M. (2006), The Influence of Avatars on OnlineConsumer Shopping Behavior, Journal of Marketing, 70, October, 19-36.

21. Hong, S., \& Kim, J. (2004), Architectural Criteria Of Website Evaluation: Conceptual Framework And Empirical Validation. Behavior \& Information Technology, 23, 5337-5357.

22. Jiang Z. \&Benbasat I. (2005), Virtual Product Experience: Effects Of Visual And Functional Control Of Products On Perceived Diagnosticity And Flow In Electronic Shopping, Journal Of Management Information Systems, 21 (3), 111-147.

23. Jin S.A.A. (2009), Avatars Mirroring The Actual Self-Versus Projecting The Ideal Self: The Effects Of Self-Priming On Interactivity And Immersion In An Exergame, Cyberpsychology \& Behavior, 12 (6), 761765.

24. Kekeff M. \& Webster C.M. (2006), Perceived Risk And Attitudes Towards Purchasing Music Online, Australian And New Zealand Marketing Academy Conference, Brisbane, Australia.

25. Kim J. \& Forsythe S. (2008), Adoption Of Virtual Try-On Technology For Online Apparel Shopping, Journal Of Interactive Marketing, 22, Spring, 45-59.

26. Koo D-M., Ju S-H., Lee M-H.\& Lee J-H.(2009), The Moderating Impact Of Atmospherics And Perceptual Curiosity On Emotions And Online Shopping Intention, Society For Marketing Advances Proceedings, 370-371.

27. Kotler, Keller (2011), Marketing Management, Prentice Hall, 14th Edition.

28. Li H., Daugherty T.\& Biocca F. (2001), Characteristics Of Virtual Experience In Electronic Commerce: A Protocol Analysis, Journal Of Interactive Marketing, 15 (3), 13-30.

29. Li H., Daugherty T. \& Biocca F. (2002), Impact of 3-D Advertising on Product Knowledge, Brand Attitude, and Purchase Intention: The Mediating Role of Presence, Journal of Advertising, 28 (3), Fall, 4357.

30. Mckinney L.N. (2004), Creating A Satisfying Internet Shopping Experience Via Atmospheric Variables, International Journal Of Consumer Studies, 28 (3), 268-283.

31. Mencarelli R. (2008), L'interaction lieu-objet comme conceptualisation de l'expérience vécue: test d'un modèle intégrateur, Recherche et Applications en Marketing, 23 (3), 51-67.

32. Oppenheimer D.M., Meyvis T. \&Davidenko N. (2009), Instructional Manipulation Checks: Detecting Satisficing To Increase Statistical Power, Journal Of Experimental Social Psychology, 45 (4), 867-872.

33. Pine, B.J. \& Gilmore J.H. (1998), Welcome to the Experience Economy, Harvard Business Review, 76 (4), 97-105.

34. Putrevu, S. \& Lord, K.R. (1994), Comparative AndNoncomparative Advertising: Attitudinal Effects Under Cognitive And Affective Involvement Conditions, Journal Of Advertising, 23, June, 77-90.

35. Suh K. \& Lee Y.E. (2005), The Effects Of Virtual Reality On Consumer Learning: An Empirical Investigation, MIS Quarterly, 29 (4), 673-697.

36. Supphellen M. \&Nysveen H, (2001), Drivers Of Intention To Revisit The Websites Of Well-Known Companies, International Journal Of Market Research, 43 (3), 341-352. 
37. Wang L.C., Baker J., Wagner J.A. \& Wakefield K. (2007), Can A Retail Web Site Be Social?, Journal Of Marketing, 71 (3), 143-157.

38. Zeithaml V. A. (1988), Consumer Perceptions Of Price, Quality, And Value: A Means-End Model And Synthesis Of Evidence, Journal Of Marketing, 52 (3), 2-22.

39. Zeithaml V.A., Berry L.L. \& Parasuraman A. (1996), The Behavioral Consequences Of Service Quality, Journal Of Marketing, 60, 31-46. 